\title{
Local Understanding and Responses to Deliberate Transmission of HIV: Experiences from Persons Receiving Antiretroviral Treatment in Rural Northeastern Tanzania
}

\author{
Mangi J $E^{1 *}$, Kagoma $\mathrm{SM}^{2}$, Idda $\mathrm{HM}^{1}$ and Knut- \\ Inge $\mathbf{K}^{3}$ \\ ${ }^{1}$ Behavioural Sciences Department, Muhimbili University \\ of Health and Allied Sciences, Dares Salaam, Tanzania \\ ${ }^{2}$ Department of Epidemiology and Biostatistics, \\ Muhimbili University of Health and Allied Sciences, \\ Dares Salaam, Tanzania \\ ${ }^{3}$ Department of Nutrition, University of Oslo, Norway \\ *Corresponding author: Mangi J . Ezekiel, \\ Department of Behavioural Sciences, School of Public \\ Health, Muhimbili University of Health \& Allied Sciences, \\ Tanzania
}

Received: December 06, 2016; Accepted: January 10, 2017; Published: J anuary 12, 2017

\begin{abstract}
As access to Antiretroviral Therapy (ART) in Tanzania has been steadily improving in recent years, there has been concern that availability of Antiretroviral Drugs (ARV) could fuel HIV transmission due to deliberate unprotected sexual practices of persons receiving antiretroviral treatment. There has been a debate about the need to enforce some institutional measures to help manage and control what has been described as the deliberate spread of HIV. However, there is no widespread consensus about what constitutes 'deliberate transmission'.

Drawing on in-depth interviews with a sample of people receiving ART and health workers providing care in a rural setting, this article examines the context in which deliberate HIV transmission is defined and the ways through which it can be controlled. The article demonstrates that people on ART face the dilemma of reducing risk of spreading HIV and a desire to maintain socially acceptable sexual and reproductive lives. Although many participants reportedly remained sexually abstinent, they also revealed that some people on treatment from within and beyond the study area were engaging in sexual behaviours perceived to amount to deliberate spread of HIV.
\end{abstract}

Despite some reservations, formal sanctions to control deliberate HIV transmission were generally highly approved by participants. The article strongly recommends for a careful examination of needs of persons on treatment and strengthened prevention in order to manage unintended consequences of ART for individuals living with HIVIAIDS and uninfected population.

Keywords: Social Control; Antiretroviral Treatment; Deliberate Transmission; HIV; Rural Tanzania

\section{Introduction}

As the HIV epidemic is evolving, there has been changing needs among persons living with HIV as well as in programmes addressing the health and social needs of people infected and affected by HIV and AIDS. One of the most important need relates to the sexual and reproductive health of persons on Antiretroviral Treatment (ART). It has been shown around the world that the majority of HIV infections are transmitted sexually or in association with pregnancy, childbirth and breastfeeding [1]. Injecting drug use and men having sex with men also contribute to HIV transmission [2] Recently, the availability of ART has changed the fertility desires of people living with HIV [3-5], raised concerns regarding safer sex and also changed symptom experiences among persons on ART [6,7]. Furthermore, in countries where ART is available, women and men experience a number of challenges, including lack of information regarding safe sex, prevention of transmission and negative attitudes towards HIV positive people having children [5,8]. Segurado and Paiva [1] have identified the difficult choices persons living with HIV face concerning sexuality, parenthood desires and family life. Despite these challenges, the availability of ART means people with HIV and AIDS will continue to live longer and pursue normal activities including recreation and procreation [7].

Recent evidence shows that increased access to ART is of public health benefit when introduced earlier in an epidemic [9] ART benefits both the infected and uninfected persons in the community since it acts as an effective prevention tool, even with high levels of drug resistance and risky sex [10]. For a long time HIV infection has been associated with sexual promiscuity and drug use, dimensions of life seen as "incurable deviancy"[5] (Availability of ART has sometimes been associated with increased risk sexual behaviours due to treatment optimism [6,11-13]. ART is also reported to greatly prolong survival with the potential to increase time available for viral transmission of resistant strains [14].

Criminalization of deliberate HIV transmission is among the most recent strategies adopted to manage the epidemic. Several countries around the world, including Africa, have passed HIV laws in an attempt to curb the spread of the pandemic $[2,15,16,17]$. The effectiveness and implications of these laws in controlling HIV and AIDS have been subject to on-going debate. UNAIDS [2] has suggested that governments should repeal current laws that 
criminalize HIV transmission and exposure with the exception of intentional transmission. In response to public outcry over the need to devise ways to manage the epidemic, the Tanzanian government passed a law to prevent and control the spread of HIV and AIDS [18]. Among other things, the law sets up criminal penalties for different actions by individuals and institutions that if violated would amount to deliberate spread of HIV [18].

Previous studies conducted in Tanzania and elsewhere have documented concerns about the potential risks of HIV spread due to increased availability of ART [19-21]. There has also been some evidence of the legal sanctions to curb the spread of the epidemic $[18,15]$. Despite the existence of a law describing intentional spread of HIV in Tanzania, there has been no attempt to systematically investigate the social definitions of deliberate spread of HIV through empirical studies. Thus, little is known about different conceptualizations of deliberate spread of HIV at the community level in Tanzania, and this study sought to feel this knowledge gap.

\section{Methods}

\section{Setting}

We conducted the study between January and March 2008 in Kahe ward, Kilimanjaro region of Tanzania, located about $30 \mathrm{~km}$ south of Moshi town. This is a rural area inhabited by several ethnic groups including the Kahe, Pare, Chagga, Sambaa, Maasai and many other ethnic groups from within and beyond the country. The nearest HIV/AIDS care and treatment clinic is located at the regional headquarters in Moshi town. The study area has been described in detail elsewhere [22].

\section{Study design}

This was a cross sectional explorative qualitative study based on In-Depth Interviews (IDIs) with persons living with HIV and AIDS who were already on ART, and with local community-based health workers.

\section{Recruitment of participants and data collection}

Participants were recruited with the assistance of local staff working with a local Non- Governmental Organization (NGO) providing care and support to people living with HIV and AIDS. The first author and local project staff approached all individuals receiving ART to describe the study and extend an invitation to participate. We also interviewed three female health workers from the NGO responsible for providing care and support to persons with HIV and AIDS in the study area. All IDIs were conducted in Kiswahili mainly at participants' homes or other locations of their own choice. IDIs used interview guide and questions covered topics related to personal experiences with illness and drug use, reproductive intentions, access to drugs, prevention of infection and opinion about ways to control deliberate spread of HIV/AIDS. IDIs took between 70-100 minutes and were audio recorded. Full transcripts were translated into English and cross checked by the first author.

The research project was approved by the Tanzania's Ministry of Health and Social Welfare and the Norwegian Committee for Medical Research Ethics. Participation in the study was preceded by a written consent from each participant.

\section{Analysis}

Our study employed an inductive approach to allow for data collection and analysis to proceed concurrently [23]. This allowed us to continuously describe, compare, contrast and interpret participants' experiences as data collection progressed. We read the interviews several times to obtain an overall understanding and gain insights into the meaning of text. All expressions and descriptions related to intentional spread of HIV that emerged throughout the data collection were condensed into categories. We organized categories of text into themes that focused on: perception about their health and the body, reproductive intentions, status disclosure and formal control of deliberate transmission of HIV.

\section{Findings}

\section{Study participants}

The study involved $22($ Female $=16$, Male $=6)$ people on ART and 3 community based health workers. More than half (11) of persons on ART were single (never married), 5 were married or living with partner, and 6 were either widowed or deserted by their sexual partners. All participants had received treatment for a considerable period-ranging from 7 months to 3 years. The participants' age ranged from 26 to 53 years. Some $(n=3)$ of the participants who initially agreed to participate declined to take part in the study.

\section{The body, reproductive intentions and deliberate HIV transmission}

Participants described several scenarios and stories about people accused of deliberately spreading the HIV through trickery, transactional sex and re-marrying after losing their partners to HIV/ AIDS. One of the male interviewees said that people living with HIV may need someone to live with in order to get support in doing some works such as assist in doing household activities due to recurrent illness.

Generally, health workers appeared to be opposed to the idea of People Living with HIV (PLHIV) getting married or re-married as this was thought to constitute deliberate attempts to get other sexual partner infected.

You will find that somebody knows that they are already (HIV) infected, yet $\mathrm{s} / \mathrm{he}$ is busy looking for someone to marry. Now how would you describe this person? Is it not looking for someone he/she should die with? (Health worker).

Health workers considered marriage or any other form of sexual relationship among HIV positive persons as endangering the lives of both partners and a child. However many said they were too preoccupied with managing their illness to be able to care for the children. When asked about the possibility of infected persons having children and establishing family while preventing further infection, one health worker responded;

Yes, we know that there are possibilities of preventing passing the virus to the child or sexual partner, but given the life difficulties already facing persons with HIV, raising a child is like adding a new problem to infected persons. You saw the conditions they live in... most of them are struggling to get their daily meal...Yet we are already having a good number of children orphaned by HIV/AIDS... attempting to have children could be as good as spreading the disease (Health worker). 
A common theme emerging from several interviews related to the existence of some form of transactional sexual practices. Economically powerful persons on ART were singled out as the main perpetrators of this form of deliberate spread of HIV. Although many cited examples of people from nearby urban centres who frequently visited the area for business or farming, they also insisted that some HIV positive men in the study area were known to spend money to buy sex. Some still emphasized the role of urban dwellers in spreading HIV in rural areas. The least mentioned behaviour described to constitute deliberate transmission of HIV like piercing a hole in a condom either during or before sexual intercourse to allow the virus to pass to the sexual partner.

\section{Status disclosure}

Both health workers and people on ART seemed to agree that HIV/AIDS was a growing problem in the village. Participants reported that there were many HIV infected people in the study area. They described those who came out and disclosed their status to partners or relatives as a small fraction of all infected people. Most participants cited failure to disclose HIV status to sexual partners as a major driver of transmission of HIV and leads to engaging in unprotected sexual relationships with uninfected individuals. Furthermore, people on ART acknowledged that more people were disclosing HIV status, but also pointed out a number of difficulties. Fear of negative family response to disclosure, marital conflict, men's reluctance to disclose, women's fear of negative consequences from spouses and elements of stigma were the main problems mentioned by participants.

If it were not for these drugs, I would be a dead man by now, if you saw me a year ago, I did not look as I do now ... was weak, very sick and bedridden. But now I can say that am doing fine because the frequency of sickness is much less now. I am stronger and my body is almost back to what I can call normal (male participant).

\section{Controlling deliberate transmission of HIV and AIDS}

Although few were aware of the new HIV prevention law, they suggested some form of government intervention to address the problem. Many proposed that the law should punish culprits because it is morally unacceptable to spread the disease. Some said that since there is evidence of people in the area allegedly known to deliberately infect others, some kind of action needed to be taken. Despite some reservations, there seemed to be a general consensus that the law to control HIV/AIDS might be good, but should have come earlier when HIV/AIDS was not as widespread as it had become.

\section{Discussion}

Results from this study have demonstrated that a number of sexual behaviours may be perceived as potential deliberate transmission of HIV/AIDS by local people on ART and health workers. The findings indicate that most participants support the establishment of some form of legal or other mechanisms to control intentional spread of HIV/AIDS. However, there are serious concerns about the practical applicability of legal sanctions to control sexual behaviours. Although there is a national law (passed in 2008) that defines various offences and remedies for persons and institutions proven to intentionally spread HIV, few participants were aware of it.

The results from our study suggest that expressing sexuality is one of the many routine activities that persons on HIV treatment wish to engage in. However, this choice is constrained by realities surrounding risks of HIV transmission. Deliberate spread of HIV could be understood as an attempt by HIV positive persons to resist the sick role that is embodied in this chronic illness. The embodiment of ART consequently forms a category of identity that is reflexively associated with deliberate spread of the disease in the community. In rural communities where ART is not fully integrated into the local discourse on treatment and healing, associating some behaviours of ARV users with deliberate spread of HIV may pave the way for misinformation and create new forms of stigma [20,22,24].

An understanding of deliberate spread of HIV must also take into account the gender dynamics and HIV status disclosure. Our findings suggest that some HIV positive persons had experienced negative consequences following status disclosure. Due to biological and social cultural reasons, women have tended to bear a significant share of the AIDS burden and they are usually the first to be diagnosed with HIV and therefore be accused of bringing the virus into the family $[25,26]$. Therefore, it is highly likely that accusations of deliberate spread of HIV will disproportionately affect women. However, this stands in contrast to the evidence showing that women are often excused from blame/accusations due to their poverty and powerlessness [20].

While women in particular have been portrayed as victims of harmful male sexual behaviours [20], the current study suggests that women constituted both perpetrators and victims. This appears to be a break from the long established beliefs that often have portrayed men as the main perpetrators of risk sexual behaviours and women as the victims. Findings also indicate that almost every participant was blaming someone else for deliberate spread of HIV. This suggests that the underlying conditions and structures might account for vulnerability to and/or motivation for deliberate spread of HIV/ AIDS. Vulnerability described by some participants is similar to what Farmer [27] has described as structural violence which tends to place blame on disease sufferers while neglecting the underlying causes. Application of formal sanctions proposed to control HIV spread may be targeting individual shortcomings instead of addressing conditions that structure people's (risk) behaviours [27].

Depiction of some ART users as transmitters of HIV may consequently affect community perspectives about care and support of HIV infected persons. As a result, HIV positive persons may lose legitimate claim to sick role and put them in ambivalent illness position before other members of community. Evidence shows that any ambivalence or deviations in socially appropriate presentation of sick role may expose persons on ART to accusations about deliberate spread of HIV and other risk sexual behaviours and assigning stigmatizing bodily identities as described in local illness discourse $[22,19]$. It has also been documented that accusations by other members of community can make ill persons be seen as faking their illness and thus be denied 'permission to get ill' [28]. Contrary to [28] findings, despite existing medical knowledge about the therapeutic benefits of ART, persons on HIV treatment in the current study appeared to have been denied 'permission to return to normalcy and express their sexuality'.

Previous evidence shows that laws criminalizing deliberate spread of HIV may increase stigma and violate the rights of persons living with HIV to life, health services and treatment [16]. The HIV 
prevention and Control Act recognizes government responsibility to ensure persons living with HIV and AIDS are accorded with basic health services. It also places responsibility on "persons who have knowledge of being infected to inform their spouse/sexual partner and to take reasonable measures and precautions to prevent the transmission of HIV to others" [18]. This also raises legal issues of whether HIV positive persons have a legal duty to disclose their HIV status before engaging in sexual activities that can lead to transmission of the virus [16].

However, the views presented here should be limited to persons on HIV treatment in the study setting. Interviews with health workers acted as a triangulation strategy to enhance reliability of findings. The fact that the HIV and AIDS prevention and control Act had not been operational when the study was carried out might have affected ability of participants to relate and reflect fully on the contents therein, thus a potential for interpretive bias. However since our study did not aim to perform a critical legal analysis of the Act, we managed to gather reflections on social definitions and suggestions on ways to control deliberate transmission of HIV.

\section{Conclusion}

The fact that issues related to deliberate transmission of HIV gain prominence in the context of increased ART availability could be a mark of new illness trajectory among HIV positive persons. There is little doubt that ARVs have made a significant impact on the lives of people living with HIV/AIDS. However, there are many issues concerning their effectiveness and impact that are still unresolved. People on ART face personal and structural challenges that affect their bodies, sexual active lives and social wellbeing. While some may wish to exercise their right to enjoy sexual lives, there is constant recognition of the risks involved in transmitting the virus to uninfected people. What constitutes deliberate HIV transmission is a function of local processes of labeling and may vary depending on persons and contexts. Likewise, ways of dealing with deliberate spread of HIV appear to reflect the socio-economic difficulties and specific individual situations of people living with HIV.

In the quest to address deliberate transmission of HIV health education efforts, need to avoid blaming the victims and invoking fear of criminal penalties. Instead, efforts should emphasize positive prevention, care, status disclosure and increased access to treatment and support services.

\section{References}

1. Segurado AC, Paiva V. Rights of HIV positive people to sexual and reproductive health: parenthood. Reproductive Health Matters. 2007; 15: 27 45.

2. UNAIDS. Criminalization of HIV Transmission. Geneva: UNAIDS. 2008.

3. Chen J L, Philips K A, Kanouse D E, Collins R L, Miu A. Fertility desires and intentions of HIV-positive men and women. Family Planning Perspectives. 2001; 33: 144-152.

4. Paiva V, Santos N, Franca-Junior I, Felipe E, Ayres JR, Segurado A. Desire to have children, gender and reproductive rights of men and women living with HIV: a challenge to health care in Brazil. AIDS Patient Care and STDs. 2007; 21: 268-277.

5. Kopelman LM, van Niekerk AA. AIDS and Africa: Introduction. Journal of Medical Philosophy. 2002; 27: 139-142.

6. Rice E, Batterham P, Rotham-Borus M. Unprotected sex among youth living with HIV before and after the advent of highly active antiretroviral therapy. Perspectives on Sexual and Reproductive Health. 2006; 38: 162-167.

7. Peltzer K, Phaswana-Mafuya N. The symptom experience of people living with HIV and AIDS in the Estern Cape, South Africa. BMC Health Services Research. 2008; 8: 271.

8. de Bruyn M. Living with HIV: challenges in reproductive health care in South Africa. Reproductive Health Matters. 2004; 8: 92-98.

9. Abbas UL, Anderson RM, Mellors JW. Potential impact of antiretroviral therapy on HIV-1 transmission and AIDS mortality in resource-limited settings. Journal of Acquired Immune Deficiency Syndrome. 2006; 41: 631-641.

10. Velasco-Hernandez JX, Gershengom HB, Blower SM. Could widespread use of combination antiretroviral therapy eradicate HIV epidemics? Lancet Infectious Diseases. 2002; 2: 487-493.

11. Bateganya M, Colfax G, Schafer L A, Kityo C, Mugynyi P, Serwadda D, et al. Antiretroviral therapy and sexual behaviour: A comparative study between antiretroviral naïve and experienced patients at an urban HIVIAIDS care and research centre in Kampala, Uganda. AIDS Patient Care and STDs. 2005; 19: $760-768$.

12. UNAIDS. Treatment education: A Critical component of efforts to ensure universal access to prevention, treatment and care. Geneva: UNAIDS. 2006.

13. Diabate S, Michel A, Constance-Kanga K. Short-term increase in unsafe sexual behaviours after initiation of HAART in Cote d'Ivoire. AIDS. 2008; 22 : 154-156.

14. Cohen MS, Gay C, Kashuba AD, Blower S, Paxton L. Antiretroviral therapy to prevent the sexual transmission of HIV-1. Annals of Internal Medicine. 2007; 146: 591-601.

15. Cameron E, Burris S, Clayton M. HIV is a virus, not a crime: ten reasons against criminal statutes and criminal prosecutions. Journal of the International AIDS Society. 2008; 11: 7.

16. Mulumba M. Sound policy or attack on health rights: Are laws criminalizing deliberate HIV transmission good for public health? 2008

17. Open Society Institute. Legislation contagion: the spread of problematic new HIV laws in Western Africa. HIVIAIDS Policy \& Review. 2007; 12: 5-11.

18. United Republic of Tanzania. HIV and AIDS (Prevention and Control) Act. Dares Salaam, Ministry of Justice and Constitutional Affairs. 2008.

19. Ezekiel MJ, Talle A, Juma JM, Mnyika KS, Klepp KI. Attitudes and perceived impact of antiretroviral drug therapy on risk sexual behaviour among young people in Kahe, Moshi rural district, Tanzania. Tanzania Journal of Health Research. 2008; 10: 203-212.

20. Roura M, Urassa M, Busza J, Mbata D, Wringe A, Zaba B. Scaling up HIV stigma? The effects of antiretroviral roll-out on stigma and HIV testing. Early evidence from rural Tanzania. Sexually Transmitted Infections. 2009; 85: 308-312.

21. Bunnell R, Ekwaru J, Wamai N, et al. Changes in sexual behaviour and risk of HIV transmission after antiretroviral therapy and prevention interventions in rural Uganda. AIDS. 2006; 20: 85-92.

22. Ezekiel M J, Talle A, Juma J M, Klepp KI. "When in the body, it makes you look fat and HIV negative": The constitution of antiretroviral therapy in loca discourse among youth in Kahe, Tanzania. Social Science and Medicine. 2009; 68: 957-964.

23. Creswell JW. Qualitative inquiry and research design: Choosing among five traditions. Thousand Oaks: SAGE Publications. 1998.

24. Castro A, Farmer P. Understanding and addressing AIDS-related stigma: from anthropological theory to clinical practice in Haiti. American Journal of Public Health, 2005; 95: 53-59.

25. UNAIDS. Review and assessment of HIVIAIDS strategies that explicitly include attention to rights. UNAIDS Global Reference Group on HIVIAIDS and Human Rights, Geneva. UNAIDS. 2004.

26. Morolake O, Stephens D, Welbourn A. Greater involvement of people living with HIV in health care. Journal of the International AIDS Society. 2009; 12: 4. 
27. Farmer $P$. Pathologies of power: health, human right and the new war on the poor. London, University of California PressFoucault, M (1990). The History of sexuality. Volume 1. Tr. Hurley. Harmondsworth: Penguin. 2005.
28. Nettleton S. 'I just want permission to be ill': Towards a sociology of medically unexplained symptoms. Social Science and Medicine. 2006; 62: 1167-1178.
Austin J HIV/AIDS Res - Volume 4 Issue 1 - 2017

ISSN : 2380-0755 | www.austinpublishing group.com

Mangi et al. () All rights are reserved
Citation: Mangi JE, Kagoma SM, Idda HM and Knut-Inge K. Local Understanding and Responses to Deliberate Transmission of HIV: Experiences from Persons Receiving Antiretroviral Treatment in Rural Northeastern Tanzania. Austin J HIV/AIDS Res. 2017; 4(1): 1033 